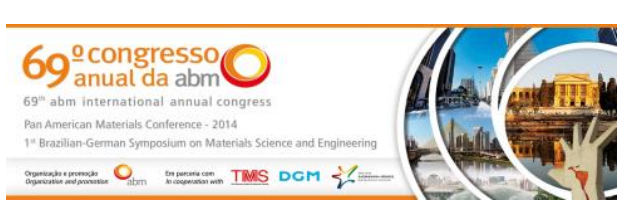

Tema: Soldagem

\title{
ANÁLISE DA SOLDABILIDADE DO FERRO FUNDIDO NODULAR SOLDADO PELOS PROCESSOS SMAW E GMAW*
}

\author{
Ivan José de Santana' \\ Matheus Henrique Moreira Souza² \\ Rachel Mary Hostues ${ }^{3}$
}

\section{Resumo}

Neste trabalho, as diferentes microestruturas, as propriedades mecânicas e a soldabilidade do ferro fundido submetido aos processos de soldagem SMAW, com a utilização de eletrodos de $\mathrm{Fe}-\mathrm{Ni}$, e GMAW mecanizado, com a aplicação de arame de $\mathrm{Fe}-\mathrm{Ni}$ e proteção de $\mathrm{Ar}-25 \% \mathrm{CO}_{2}$, foram investigadas e comparadas. Dentro deste contexto, após a realização de testes de soldagem, com e sem a aplicação de préaquecimento, utilizando diferentes parâmetros de soldagem, os cordões de solda foram avaliados por meio de microscopia óptica e microscopia eletrônica de varredura, assim como pela análise dos perfis de micro-dureza e da composição química do arame e do material depositado. Foi possível avaliar a influência da aplicação de diferentes parâmetros elétricos de soldagem, a utilização ou não de pré-aquecimento nas microestruturas geradas nas zonas fundidas, parcialmente fundidas e termicamente afetadas dos cordões obtidos, assim como as propriedades mecânicas.

Palavras-chave: Soldagem de ferro fundido; Microestrutura e propriedades mecânicas do ferro fundido soldado.

\section{ANALISYS OF THE WELDABILITY OF THE NODULAR CAST IRON WELDED BY THE PROCESS SMAW AND GMAW}

\section{Abstract}

This study evaluated and compared the microstructures, mechanical properties and weldability of a cast iron submitted to a SMAW welding process using a $\mathrm{Fe}-\mathrm{Ni}$ electrode and a GMAW automatic weldingusing a solid $\mathrm{Fe}-\mathrm{Ni}$ wire and $\mathrm{Ar}-25 \% \mathrm{CO}_{2}$ as a shielding gas. The experiments were realized using different welding parameters, with and without preheating stage. The wire and the deposited metal chemical composition were determined and the weld beads were analyzed by optical and scanning electron microscopy and microhardness profiles. It was possible to evaluate the influence of the electrical parameters and preheated stage in the fusion, partially fusion and heat affected zones microstrutuctures, even as the mechanical properties.

Keywords: Weldability of the cast iron; Microstrutuctures and mechanical properties of the casting iron welded.

1 Engenheiro Mecânico, Doutor, Professor, Departamento de Engenharia de Materiais, CEFET-MG, Belo Horizonte, MG, Brasil.

2 Engenharia de Materiais, Graduando, aluno, Departamento de Engenharia de Materiais, CEFETMG, Belo Horizonte, MG, Brasil.

3 Engenheira Mecânica, Doutora, Professora, Departamento de Engenharia de Materiais, CEFETMG, Belo Horizonte, MG, Brasil.

\footnotetext{
* Contribuição técnica ao $69^{\circ}$ Congresso Anual da ABM - Internacional e ao 14ํㅡㄹ ENEMET - Encontro Nacional de Estudantes de Engenharia Metalúrgica, de Materiais e de Minas,21 a 25 de julho de 2014, São Paulo, SP, Brasil.
} 


\section{INTRODUÇÃO}

Comparando a soldagem dos ferros fundidos com a dos aços, os primeiros são mais difíceis de serem soldados [1-4], mas com o entendimento da natureza do material e de suas características, podem ser adotados alguns procedimentos com o objetivo de eliminar e ou contornar estas dificuldades [4]. De uma maneira geral, a dificuldade na soldagem dos ferros fundidos se origina nas seguintes características: alto teor de carbono, baixa ductilidade, baixa condutividade térmica e alto coeficiente de expansão térmica [4,5]. Além dessas características podem ocorrer na ZTA a formação da martensita e na zona parcialmente fundida o desenvolvimento de uma rede de carbonetos extremamente frágeis [2,4]. Para minimizar os problemas devido à formação de microestruturas frágeis na zona fundida (ZF) e na zona termicamente afetada (ZTA), as técnicas mais utilizadas são o preaquecimento e o pósaquecimento dos componentes soldados [4,6]. A necessidade de pré-aquecer as peças depende de seu tamanho e de sua forma geométrica, do grau de distorção aceitável, do tipo de ferro fundido e do metal de deposição [4]. A utilização desta técnica permite reduzir o gradiente térmico formado entre a região soldada, com picos de temperatura acima da temperatura de fusão, e as regiões adjacentes, que, em geral, permanecem com temperaturas próximas à ambiente. Desta forma, o preaquecimento pode prevenir a formação de trincas, reduzir tensões residuais e distorções e diminuir as taxas de resfriamento. Por outro lado, pode possibilitar o aumento da zona de fusão e da zona termicamente afetada $[4,7,8]$. Os processos de soldagem a arco elétrico com a utilização de eletrodos revestidos (SMAW), a soldagem a arco elétrico com a utilização de arame e uma fonte externa de gás de proteção (GMAW) e o processo de soldagem com chama oxiacetilênica (OFW) são, de acordo com a literatura, os mais aplicados na soldagem dos ferros fundidos [4]. Contudo, alguns pesquisadores vêem avaliando os processos de soldagem por feixe de elétrons e por fricção $[9,10]$. Quando se solda ferro fundido utilizando o processo de soldagem SMAW aplica-se, basicamente, as seguintes ligas como material de deposição: (1) ligas aços com médio e baixo teor de carbono, (2) ligas de ferro fundido e (3) ligas de ferro-níquel ou níquel puro [4].

Neste trabalho, buscou-se avaliar as diferentes microestruturas e, consequentemente, as propriedades mecânicas e a soldabilidade especificamente do ferro fundido nodular quando submetido ao processo de soldagem SMAW com e sem a aplicação de pré-aquecimento e utilizando diferentes tipos de eletrodos revestidos. Após a caracterização dos materiais de consumo e a execução de testes de soldagem, foram obtidas imagens da micro e da macroestrutura dos cordões depositados, por meio de microscopia óptica. Foram obtidos os perfis de dureza Vickers, das zonas fundidas e da ZTA, por meio de microdureza Vickers, e obtevese, também, a composição química da zona de fundida, por espectroscopia por energia dispersiva de raios $\mathrm{X}$. Foi possível avaliar a influência dos diferentes tipos de eletrodos revestidos e da utilização ou não de pré-aquecimento nas propriedades mecânicas e características microestruturais das zonas fundidas e da ZTA dos cordões obtidos.

\section{MATERIAIS E MÉTODOS}

Foram utilizados neste trabalho para a realização dos testes de soldagem (deposição de cordões sobre tubo) tubos de ferro fundido nodular centrifugado com revestimento interno de argamassa (Figura 1a). Esses tubos são aplicados, por

\footnotetext{
* Contribuição técnica ao $69^{\circ}$ Congresso Anual da ABM - Internacional e ao 14ํㅡㄹ ENEMET - Encontro Nacional de Estudantes de Engenharia Metalúrgica, de Materiais e de Minas,21 a 25 de julho de 2014, São Paulo, SP, Brasil.
} 


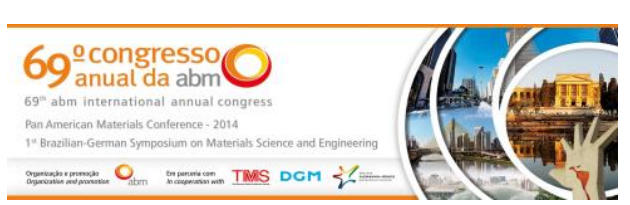

Tabela 2 - Características dos eletrodos e parâmetros de soldagem recomendados. Fonte: Fabricantes.

\begin{tabular}{c|c|c|c|c}
\hline Elemento / Eletrodo & $\begin{array}{c}\text { Diâmetro } \\
{[\mathrm{mm}]}\end{array}$ & $\begin{array}{c}\text { Comprimento } \\
{[\mathrm{mm}]}\end{array}$ & $\begin{array}{c}\text { Corrente } \\
{[\mathrm{A}]}\end{array}$ & Polaridade \\
\hline Eletrodo "A" & 2,5 & 350 & 50 e 70 & $\mathrm{CA} \mathrm{e} \mathrm{CC} \mathrm{+}$ \\
\hline Eletrodo "B" & 3,2 & 355 & 90 a 120 & $\mathrm{CA}$ e CC + \\
\hline Eletrodo "C" & 2,5 & 350 & 45 a 80 & $\mathrm{CA} \mathrm{e} \mathrm{CC+}$ \\
\hline
\end{tabular}

A Tabela 3 revela os parâmetros de soldagem utilizados nos experimentos com e sem pré-aquecimento.

Tabela - 3 - Parâmetros elétricos utilizados nos testes de soldagem sem pré-aquecimento.

\begin{tabular}{|c|c|c|c|c|c|}
\hline Teste & $\begin{array}{c}\mathrm{V}_{\mathrm{d}}{ }^{1} \\
{[\mathrm{~mm} / \mathrm{min}]}\end{array}$ & $\begin{array}{l}\mathrm{V}_{0}{ }^{2} \\
{[\mathrm{~V}]}\end{array}$ & $\begin{array}{c}\mathrm{V}_{\mathrm{a}}{ }^{3} \\
{[\mathrm{~m} / \mathrm{min}]}\end{array}$ & $\begin{array}{l}\mathrm{DBCP}^{4} \\
{[\mathrm{~mm}]}\end{array}$ & $\begin{array}{c}\text { Gás proteção } \\
{[\mathrm{L} / \mathrm{min}]}\end{array}$ \\
\hline $01 \mathrm{SP}-01 \mathrm{CP}$ & 0,175 & 30 & 3,25 & 15 & 15 \\
\hline 02SP - 02CP & 0,175 & 31 & 3,25 & 15 & 15 \\
\hline 03SP - 03CP & 0,175 & 32 & 3,25 & 15 & 15 \\
\hline 04SP - 04CP & 0,175 & 33 & 3,25 & 15 & 15 \\
\hline
\end{tabular}

Obs: $S P$ - sem pré-aqueximento, $C P$ - com pré-aquecimento, $V_{d}$-Velocidade de deslocamento da tocha, $V_{0}-$ tensão em vazio da fonte, $V_{a}$ - velocidade de alimentação do arame, $D B C P$ - Distância entre o bico de contato e a peça, (5) Ar25- $\mathrm{CO}_{2}$ e (6) - corrente média de soldagem.

A Tabela 4 revela as características do arame e os parâmetros operacionais recomendadas pelo fabricante.

Tabela 4 - Características do arame (maciço) e parâmetros operacionais de soldagem recomendados. Fonte: Fabricante.

\begin{tabular}{c|c|c|c|c|c|c}
\hline Arame & $\begin{array}{c}\text { Diâmetro } \\
{[\mathrm{mm}]}\end{array}$ & $\begin{array}{c}\text { Tensão } \\
{[\mathrm{V}]}\end{array}$ & $\begin{array}{c}\text { Corrente } \\
{[\mathrm{A}]}\end{array}$ & $\begin{array}{c}\text { DBCP } \\
{[\mathrm{mm}]}\end{array}$ & $\begin{array}{c}\text { Gás de proteção } \\
75 \% \mathrm{Ar}+25 \% \mathrm{CO}_{2}\end{array}$ & $\begin{array}{c}\text { Tranferência } \\
\text { metálica }\end{array}$ \\
\hline $\mathrm{Ni}-\mathrm{Fe}$ & 1,2 & $26-29$ & $100-175$ & $15 \pm 3$ & $12-16 \mathrm{l} / \mathrm{min}$ & Spray \\
\hline
\end{tabular}

Os testes, soldagem SMAW e GMAW, eram validados, de maneira qualitativa, como apropriados considerando o aspecto visual e a morfologia. Em relação a aspectos que poderiam dar um enfoque quantitativo, nenhum cordão obtido apresentou descontinuidades, tais como mordedura, poros, inclusão de escória, trincas, etc.

Após a realização dos testes de soldagem, os corpos-de-prova foram cortados para o preparo das amostras destinadas aos ensaios metalograficos, microdureza e análise química. Para a análise microestrutural, as amostras foram preparadas e atacadas com reativo Nital $2 \%$ ou Nital $5 \%$. Os valores de dureza foram obtidos por meio de ensaio de dureza Vickers e os perfis de dureza da ZF, ZPF e ZTA dos corpos-de-prova foram obtidos por meio do ensaio de micro-dureza Vickers (carga de $50 \mathrm{gf}$, tempo de aplicação de $15 \mathrm{~s}$ ). As análises químicas semi-quantitativas dos eletrodos, assim como dos cordões de solda, foram realizada utilizando um equipamento de espectroscopia por energia dispersiva de raios $X$ (EDX). Nos cordões depositados a análise química foi realizada próximo à extremidade dos cordões depositados $(2 \mathrm{~mm})$, o que pode ser observado na Figura 2. Este equipamento, em função do seu detector, não é capaz de identificar o carbono.

\footnotetext{
* Contribuição técnica ao $69^{\circ}$ Congresso Anual da ABM - Internacional e ao 14ํㅡㄹ ENEMET - Encontro Nacional de Estudantes de Engenharia Metalúrgica, de Materiais e de Minas,21 a 25 de julho de 2014, São Paulo, SP, Brasil.
} 

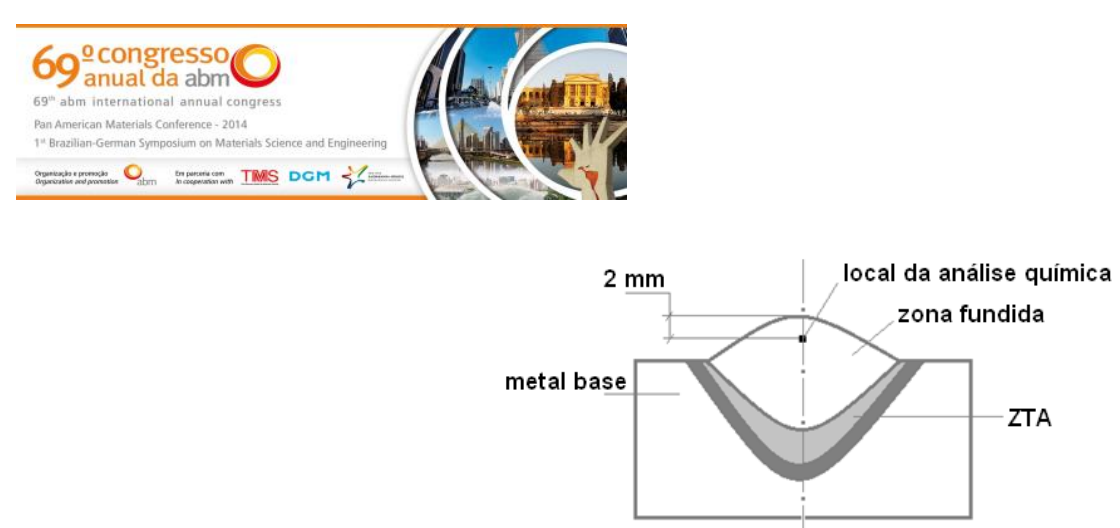

Figura 2 - Desenho esquemático região onde foram realizadas as análises químicas nos cordões de solda.

As diluições dos cordões de solda foram calculadas dividindo a área fundida no metal base pela área fundida total (área fundida no metal base mais a área do reforço), representadas na figura 3.

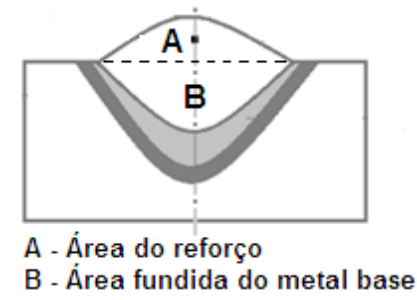

Figura 3 - Desenho esquemático indicando a área da região do metal base fundido e a área do reforço.

\section{RESULTADOS E DISCUSSÃO}

A Figura 4 ( $a$ e b) exibe imagens da microestrutura do material do tubo usado nos testes de soldagem obtidas por microscopia ótica e microscopia eletrônica de varredura (MEV), respectivamente. Pode-se observar que se trata de um ferro fundido nodular com matriz ferrítica $[1,2,4,5]$, o que confere ao material baixa dureza e, aliado à morfologia da grafita nessa situação, boa ductilidade, podendo chegar a algo próximo de $20 \%$ de alongamento em ensaios de tração [5].

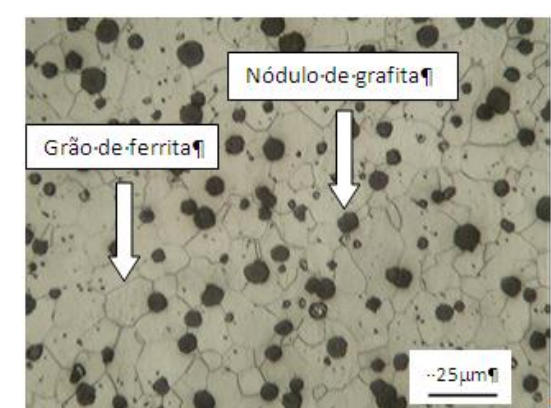

(a)

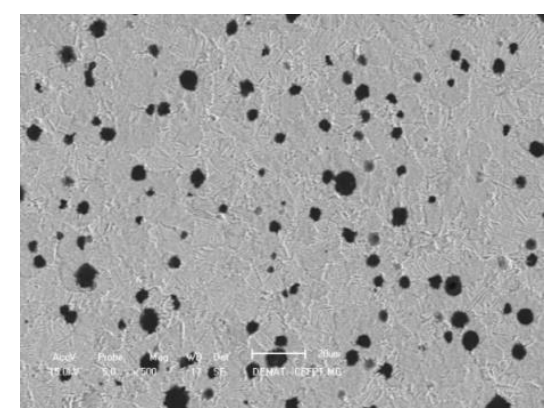

(b)

Figura 4 - Imagens da microetrutura do material do tubo: (a) microscopia ótica, (b) MEV. Ataque Nital $2 \%$.

A Tabela 5 exibe a composição química do material do tubo e, como pode ser observado, não foi possível identificar o teor de carbono em função das limitações do equipamento, como descrito na metodologia. Porém, essa análise permitiu verificar a inexistência de diferentes elementos de liga importantes, tal como o Níquel. Além disso, possibilitou a determinação dos valores aproximados de manganês e silício e a constatação de que se trata de uma liga de ferro fundido convencional e comercial [2,5].

\footnotetext{
* Contribuição técnica ao $69^{\circ}$ Congresso Anual da ABM - Internacional e ao 14ํㅡㄹ ENEMET - Encontro Nacional de Estudantes de Engenharia Metalúrgica, de Materiais e de Minas,21 a 25 de julho de 2014, São Paulo, SP, Brasil.
} 
Tabela 5 - Composição do tubo. Fonte: AUTOR

\begin{tabular}{c|c}
\hline Elemento (\%) & Material do tubo \\
\hline Ferro + Carbono* & 97,98 \\
\hline Silício & 2,57 \\
\hline Manganês & 0,27 \\
\hline Fosforo & 0,18
\end{tabular}

Obs: * O carbono não é detectado pelo equipamento utilizado na análise, como relatado no item 2, e para fechar o balanço de massa a porcentagem de ferro é ajustada.

A Tabela 6 exibe os resultados referentes à composição química da alma dos três eletrodos utilizados nos testes. Percebe-se que apenas o definido como Eletrodo " $C$ " apresenta níquel na composição química de sua alma.

Tabela 6 - Composição da alma dos eletrodos. Fonte: AUTOR

\begin{tabular}{c|c|c|c}
\hline Elemento / Eletrodo & Eletrodo "A" & Eletrodo "B" & Eletrodo "C" \\
\hline Ferro + Carbono & 99,3 & 99,3 & 38,2 \\
\hline Níquel & xxxxx & xxxxx & 60,5 \\
\hline Manganês & 0,5 & 0,6 & 0,7 \\
\hline Silício & 0,2 & xxxxx & 0,2 \\
\hline Cromo & xxxxx & 0,1 & 0,4 \\
\hline \multicolumn{4}{|c}{}
\end{tabular}

A Tabela 7 exibe os resultados referentes à composição química do revestimento dos três eletrodos utilizados. Pôde se observar diferenças significativas nas quantidades dos compostos presentes, fato que deve estar associado ao tipo de revestimento de cada eletrodo (por exemplo: revestimento básico) [4,11, 12 e 13] e a existência de níquel no revestimento.

Tabela 7 - Composição do revestimento dos eletrodos. Fonte: AUTOR

\begin{tabular}{c|c|c|c}
\hline Elemento / Eletrodo & $\begin{array}{c}\text { Eletrodo "A" } \\
\text { (mastersolda) }\end{array}$ & $\begin{array}{c}\text { Eletrodo "B" } \\
(4005)\end{array}$ & $\begin{array}{c}\text { Eletrodo "C" } \\
(9258)\end{array}$ \\
\hline $\mathrm{BaO}$ & 42,8 & 0,5 & 1,4 \\
\hline $\mathrm{NiO}$ & 33,8 & 40,5 & xxxxx \\
\hline $\mathrm{CuO}$ & 5,6 & 2,3 & $\mathrm{xxxxx}$ \\
\hline $\mathrm{CaO}$ & 8,3 & 14,3 & 68,3 \\
\hline $\mathrm{SiO}_{2}$ & 4,2 & 21,8 & 14,2 \\
\hline $\mathrm{Fe}_{2} \mathrm{O}_{3}$ & 0,8 & 1,5 & 9,0 \\
\hline $\mathrm{Outros}$ & Balanço & Balanço & Balanço \\
\hline
\end{tabular}

A Tabela 8 exibe os resultados referentes à composição química do arame utilizado no processo GMAW. Percebe-se que o níquel é o elemento predominante, o que se justifica pelo fato de ser um elemento gamagêneo, pela sua baixa condutividade térmica e ao seu baixo coeficiente de dilatação volumétrica, fatores que favorecem a soldabilidade dos ferros fundidos [4].

A Figura 5 exibe exemplos de fotomacrografias obtidas das microestruturas geradas quando foi utilizado o processo SMAW, eletrodo do tipo "C", com e sem préaquecimento. Foi possível perceber que, em função do pré-aquecimento, a extensão da ZTA aumenta.

\footnotetext{
* Contribuição técnica ao 69 Congresso Anual da ABM - Internacional e ao 14ํㅡㄹ ENEMET - Encontro Nacional de Estudantes de Engenharia Metalúrgica, de Materiais e de Minas,21 a 25 de julho de 2014, São Paulo, SP, Brasil.
} 


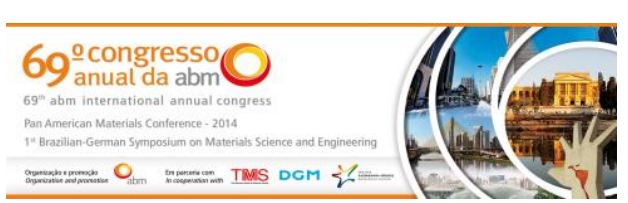

Tabela 8 - Composição do arame. Fonte: AUTOR

\begin{tabular}{c|c}
\hline Elemento & Arame Eletrodo (\%) \\
\hline Ferro +Carbono & 36,25 \\
\hline Níquel & 60,83 \\
\hline Cromo & 1,24 \\
\hline Manganês & 0,97 \\
\hline Silício & 0,71
\end{tabular}

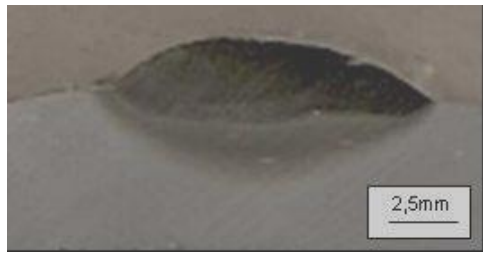

(a)

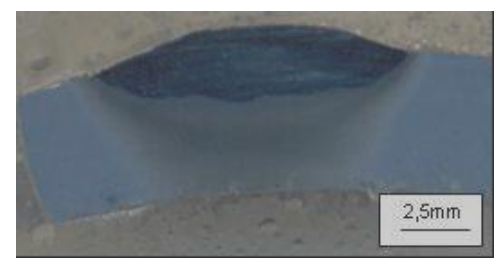

(b)

Figura 5 - Fotomacrografia dos cordões de soda: (a) Eletrodo "C", sem pré-aquecimento: (b) Eletrodo "C", com pré-aquecimento". Ataque Nital 5\%.

A Tabela 9 exibe os resultados referentes à composição química dos cordões depositados, percebe-se que todos os eletrodos forneceram níquel ao metal depositado reforçando a possibilidade da existência deste elemento no revestimento dos eletrodos "A" e "B".

Tabela - 9 - Composição dos cordões depositados - \% em peso, testes sem pré-aquecimento.

\begin{tabular}{c|c|c|c}
\hline Elemento / Corpo de Prova & $\begin{array}{c}\text { Eletrodo "A" } \\
\text { (mastersolda) }\end{array}$ & $\begin{array}{c}\text { Eletrodo "B" } \\
(4005)\end{array}$ & $\begin{array}{c}\text { Eletrodo "C" } \\
(9258)\end{array}$ \\
\hline Ferro & 72,0 & 83,4 & 63,9 \\
\hline Níquel & 24,5 & 13,2 & 33,0 \\
\hline Silício & 1,2 & 1,2 & 1,1 \\
\hline Manganês & 0,6 & 0,8 & 0,5 \\
\hline Cobre & XXXXX & 0,7 & XXXXX \\
\hline Outros & Balanço & balanço & Balanço \\
\hline
\end{tabular}

Os resultados apresentados na tabela 9 devem ser considerados para a identificação dos elementos presentes nos cordões depositados e não para uma análise de valores absolutos. Tal observação se justifica uma vez que os valores de diluição nos cordões foram diferentes, como pode ser observado na tabela 10.

Tabela - 10 - Composição dos cordões depositados - \% em peso, testes sem pré-aquecimento.

\begin{tabular}{c|c|c|c}
\hline Corpo de prova & $\begin{array}{c}\text { Eletrodo "A" } \\
\text { (mastersolda) }\end{array}$ & $\begin{array}{c}\text { Eletrodo "B" } \\
(4005)\end{array}$ & $\begin{array}{c}\text { Eletrodo "C" } \\
(9258)\end{array}$ \\
\hline Diluição (\%) & 49,0 & 64,0 & 44,0 \\
\hline
\end{tabular}

A Figura 6 exibe exemplos de imagens obtidas a partir das microestruturas geradas quando foi utilizado o processo SMAW, eletrodo do tipo "C", sem pré-aquecimento, com pré-aquecimento e com pré-aquecimento e normalizado, respectivamente. Os cordões obtidos sem pré-aquecimento apresentaram uma estrutura austenítica na ZF (zona fundida), um pouco de ferro fundido branco próximo a ZPF (zona parcialmente fundida), com agulhas de cementita num fundo de ledeburita [1-3,10-12], e, também, ferro fundido nodular com matriz martensítica no início da ZTA.

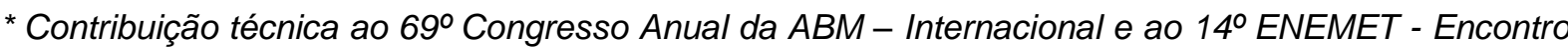
Nacional de Estudantes de Engenharia Metalúrgica, de Materiais e de Minas,21 a 25 de julho de 2014, São Paulo, SP, Brasil.
} 


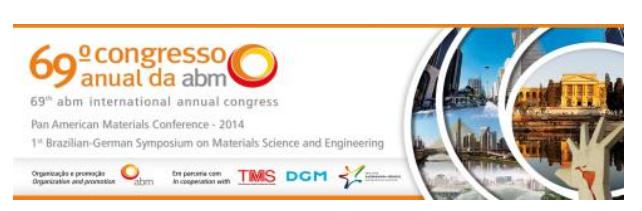

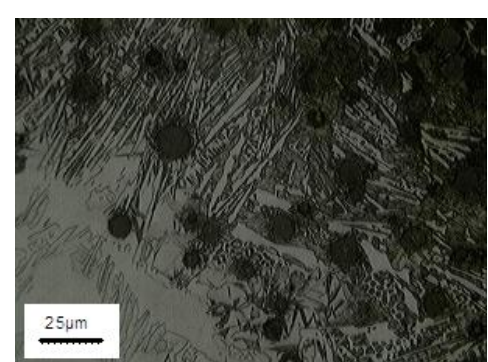

(a)

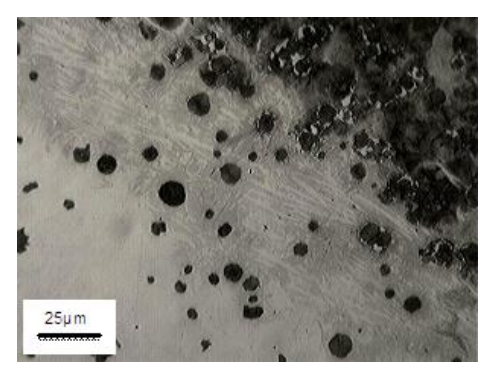

(c)

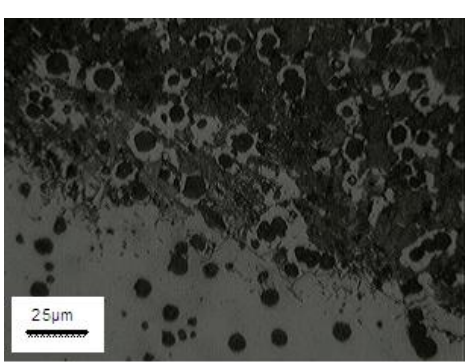

(b)

Figura 6 - Fotomicrografia dos cordões de soda: (a) Eletrodo "C", sem pré-aquecimento: (b) Eletrodo "C", com pré-aquecimento" e (c) Eletrodo "C", com pré-aquecimento e normalizado. Ataque Nital $2 \%$.

Pôde-se, também, verificar que a aplicação do pré-aquecimento de $300^{\circ} \mathrm{C}$ fez com que praticamente não houvesse $\mathrm{o}$ aparecimento da ledeburita, das agulhas de cementita, e de martensita na ZPF e na ZTA [2,11, 12,14]. Já com a aplicação do pré-aquecimento de $300^{\circ} \mathrm{C}$ e normalização, percebe-se na ZPF e na ZTA, a estrutura de um ferro fundido nodular com matriz ferrítica e perlítica.

A Figura 7 exibe exemplos de imagens obtidas a partir das macroestruturas geradas quando foram realizados os testes com o processo GMAW, testes 04SP e 04CP, respectivamente.

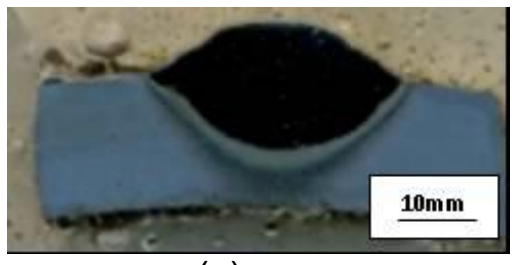

(a)

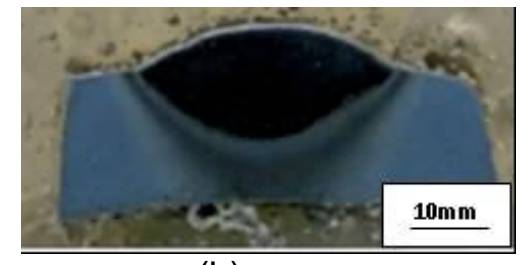

(b)

Figura 7 - Imagens da macroestrutura dos cordões de soda: (a) teste "04SP", sem pré-aquecimento, (b) teste "04CP", com pré-aquecimento. Ataque Nital $2 \%$.

Percebe-se que, em função da aplicação ou não do pré-aquecimento, a extensão da ZTA sofre grande variação, assim como oi observado nos testes com SMAW . Os testes realizados sem pré-aquecimento apresentam uma extensão termicamente afetada muito menor em comparação com os testes realizados com préaquecimento. Isto se deve à ocorrência de temperaturas de pico acima da temperatura de recristalização em regiões mais afastadas do cordão, possibilitando, mudanças de fases, alteração na morfologia da grafita, crescimento ou refino de grão, que dependerá da posição em relação à poça de fusão $[1,2,4,5]$.

A Tabelas 11 exibe os resultados referentes as análises químicas realizadas nos cordões de solda depositados pelo processo GMAW.

Verificou-se, mesmo com valores de diluição maiores do que os observados nos testes SMAW, teores de níquel acima de $25 \%$. O níquel é um elemento gamagêneo, portanto tende a estabilizar a austenita na temperatura ambiente, o que, de certa forma pode favorecer a soldabilidade do ferro fundido uma vez que esta fase permite maior deformação plástica da zona fundida que possibilita uma absorção de tensões e dificulta a propagação de trincas $[1,2,5,6]$.

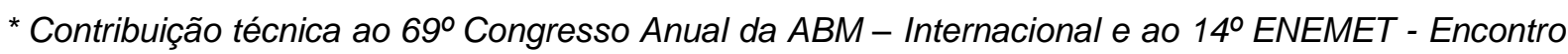
Nacional de Estudantes de Engenharia Metalúrgica, de Materiais e de Minas,21 a 25 de julho de 2014, São Paulo, SP, Brasil.
} 


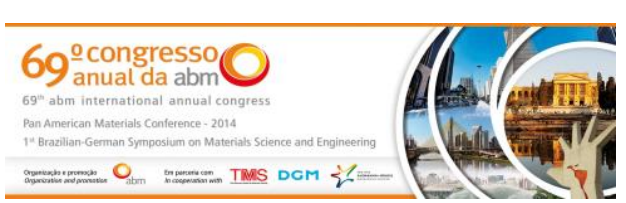

aliada às tensões residuais, frequentemente geradas nos procedimentos de soldagem, podem levar ao aparecimento de trincas e até mesmo a fratura da junta, fato que contribui para a baixa soldabilidade atribuída aos ferros fundidos.

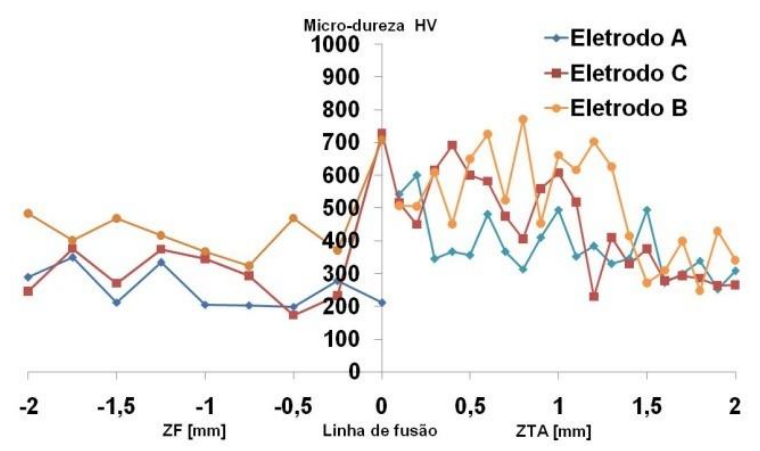

(a)

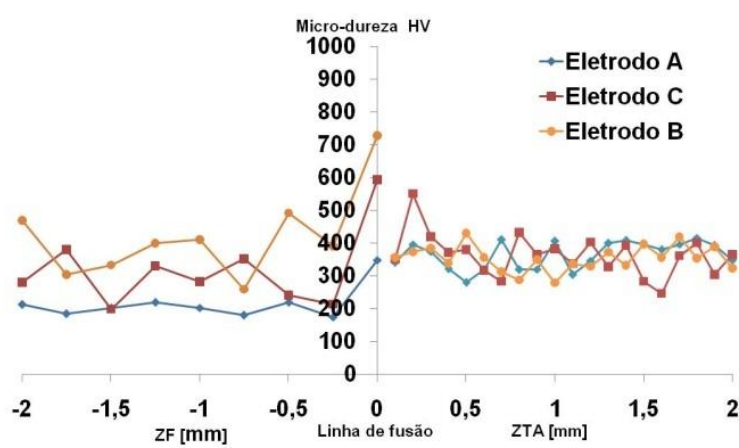

(b)

Figura 9 - Perfil de dureza dos cordões: (a) SMAW - sem pré-aquecimento, (b) SMAW - com préaquecimento.

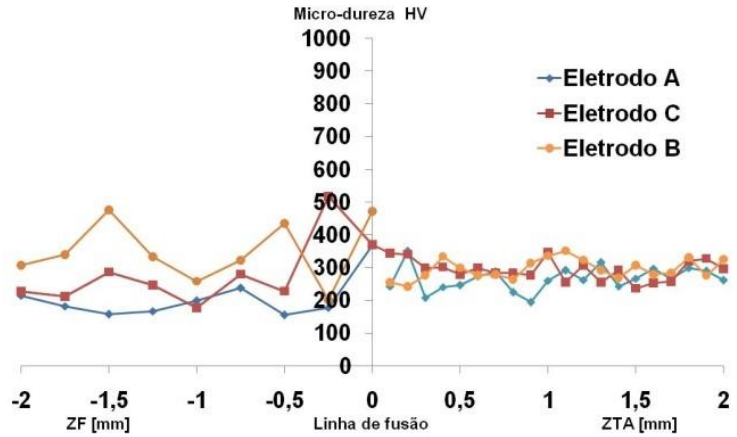

(a)

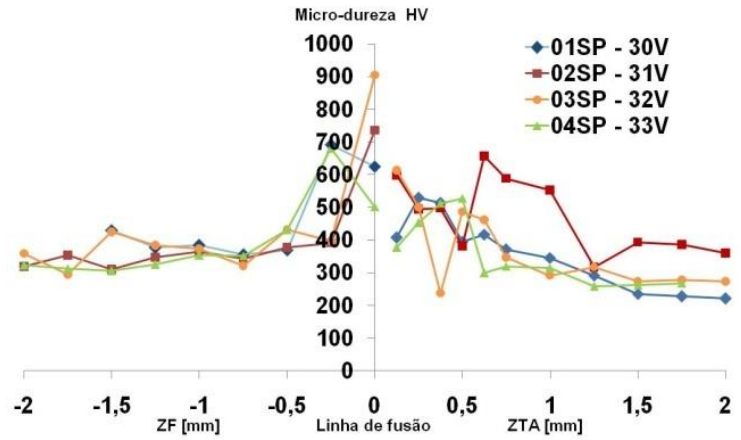

(b)

Figura 10 - Perfil de dureza dos cordões: (a) SMAW - com pré-aquecimento e normalizado, (b) GMAW - sem pré-aquecimento.

Por fim, percebe-se que o processo GMAW é uma excepcional opção de processo para a soldagem de ferro fundido possibilitando, repetibilidade, fácil mecanização ou automatização, e obtenção de cordões com morfologia e microestruturas que podem ser ajustadas a condições específicas [15].

\section{CONCLUSÃO}

1) A adição de níquel ao cordão de solda por meio do revestimento dos eletrodos e não da alma se revelou eficiente, considerando que os eletrodos " $A$ " e " $B$ " geraram cordões depositados com este elemento presente, além de microestruturas e perfil de microdureza similares ao eletrodo " $\mathrm{C}$ ".

2) O pré-aquecimento a $300^{\circ} \mathrm{C}$ favoreceu a diminuição de uma estrutura típica de um ferro fundido coquilhado, pela diminuição da velocidade de resfriamento. Com isso, verificou-se uma diminuição nos valores de dureza observados na ZF, ZPF e ZTA.

3) O processo GMAW é uma excepcional opção, também, para a soldagem de ferro fundido, possibilitando, como para outros materiais, após a determinação dos parâmetros de soldagem adequados, repetibilidade, fácil mecanização ou automatização, e obtenção de cordões com morfologia e microestruturas que podem ser ajustadas a condições específicas e desejadas.

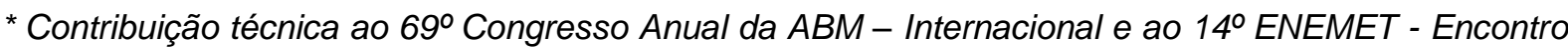
Nacional de Estudantes de Engenharia Metalúrgica, de Materiais e de Minas,21 a 25 de julho de 2014, São Paulo, SP, Brasil. 


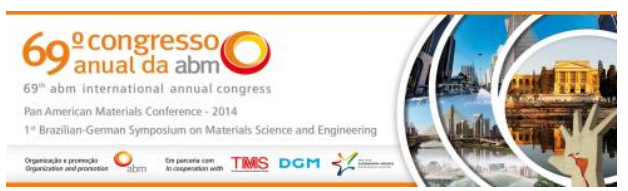

4) A aplicação de pré-aquecimento fez com que a extensão da ZTA aumentasse, porém os valores máximos de dureza ficam bem menores em relação à condição de soldagem sem pré-aquecimento.

5) $\mathrm{O}$ pré-aquecimento a $300^{\circ} \mathrm{C}$, também, possibilitou uma maior diluição entre o metal de deposição e o metal base, o que certamente contribuiu para a diminuição da dureza na ZPF, porém para algumas situações isto possa ser uma descontinuidade relevante.

6) Percebe-se que, em função dos resultados obtidos com pré-aquecimento, a estrutura martensítica observada nos cordões de solda pode ser mais facilmente eliminada em relação à estrutura típica de ferro fundido branco, com a aplicação de tratamento térmico de normalização.

\section{Agradecimentos}

Os autores agradecem ao CNPq pelo apoio, assim como ao Departamento de Engenharia de Materiais (DEMAT - CEFET MG) pela possibilidade de utilização da infra-estrutura laboratorial e a Eutectic do Brasil pelo fornecimento dos arames empregados nos experimentos.

\section{REFERÊNCIAS}

1 Chiaverini V. Aços e ferros fundidos. 7 ed. São Paulo: Associação Brasileira de Metalurgia e Materiais - ABM, 2005. 599p.

2 Colpaert H. Metalografia dos produtos siderúrgicos comuns. 4 ed. São Paulo: Blücher, 2008. 672p.

3 Ishizaki K, Mora JG, Salas MM, Davila A.. Simulation Study on Ductile Cast Iron Welding by Austenitic Filler Metal. Tansactions of the Japan Welding Society, 1984; 15, (2): 3-8.

4 Paris AAF. Tecnologia da soldagem de ferros fundidos. Santa Maria: UFSM, 2003. $144 p$.

5 Guesser WL. Propriedades mecânicas dos ferros fundidos. São Paulo: Blücher, 2009. 344p.

6 Pouranvari M. On the weldability of gray cast iron using nickel based filler metal. Materials and Desing, 2010; 31: 3253-3258.

7 El-Banna EM. Effect of preheat on welding of ductile cast iron. Materials Letters, 1999; 41: $20-26$.

8 Hatate M, Shiota T, Abe N, Amano M, Tanaka T. Bonding characteristics of spheroidal graphite cast iron and mild steel using electron beam welding process. Vacuum, 2003; 73: 667-71.

9 Sawada YK, Nakamura M. Lapped friction stir welding between ductile cast irons and stainless steels. Quart J Jpn Weld Soc, 2009; 27: 176-82.

10 El-Banna EM, Nageda MS, Abo El-Saadat MM. Study of restoration by welding of perlitic ductile cast iron. Materials Letters, 2000; 42: 311-320.

11 Cary HB. Modern welding technology. 4 ed. New Jersey: Prentice Hall, 1998.780p.

12 ASM. Gas-metal arc welding. Welding Handbook. 2.ed., v.6, 1994. p. 569-581.

13 Marques PV, Modenesi PJ, Bracarense AQ. Soldagem - fundamentos e tecnologia. 3. ed. rev. Belo Horizonte: Editora UFMG, 2009. 362p.

14 Behnam MMJ, Davami P, Varahram N. Effect of cooling rate on microstructure and mechanical properties. Mater. Sci. Eng. A, 2010: 1-6, doi:10.1016/j.msea.2010.09.087.

15 Scotti A, Ponomarev V. Soldagem MIG/MAG: melhor entendimento, melhor desempenho. São Paulo: Editora Artliber, 2008. 284p.

\footnotetext{
* Contribuição técnica ao $69^{\circ}$ Congresso Anual da ABM - Internacional e ao 14ํㅡㄹ ENEMET - Encontro Nacional de Estudantes de Engenharia Metalúrgica, de Materiais e de Minas,21 a 25 de julho de 2014, São Paulo, SP, Brasil.
} 